\title{
DOS ENIGMAS DE LO POLÍTICO EVALUADOS A LA LUZ DE LAS IDEAS DE ÉTIENNE DE LA BOÉTIE Y DE M. FOUCAULT
}

\author{
DOIS ENIGMAS DO POLÍTICO AVALIADOS A LUZ DAS IDEIAS DE ÉTIENNE DE LA \\ BOÉTIE E M. FOUCAULT
}

\section{TWO POLITICAL ENIGMAS ASSESSED IN LIGHT OF THE IDEAS OF ÉTIENNE DE LA BOĖTIE AND M. FOUCAULT}

\section{DEUX ÉNIGMES DU POLITIQUE ÉV ALUÉES À LA LUMIÈRE DES IDÉES D’ÉTIENNE DE LA BOÉTIE ET DE MICHEL FOUCAULT}

\section{利用 ÉTIENNE DE LA BOĖTIE 和福柯的思想分析政治家的两个不解之谜}

DOI: 10.5533/1984-2503-20135301

Andrés Cappelletti ${ }^{1}$

\section{RESUMEN}

Dos misteriosos enigmas recubren los nexos entre los humanos y las relaciones políticas que ellos mismos crean. El primero a la desigual relación entre los pocos que gobiernan y las multitudes gobernadas. ¿Cómo es posible que las personas procuren ser gobernadas y controladas? ¿Por qué los hombres luchan por su servidumbre como si se tratara de su salvación? Estos interrogantes fueron formulados por Étienne de La Boétie en el siglo XVI. El otro enigma, en estrecho vínculo con el anterior, alude a la pasión o amor por el poder, al lazo que el hombre establece con el poder; la seducción que el poder ejerce sobre el hombre que lo detenta. En el presente ensayo intentaremos evaluar ambos enigmas a través de la utilización, por un lado, de las ideas contenidas en el Discurso de la servidumbre voluntaria y, por otro, de los conceptos foucaultianos de poder y de gobierno.

Palabras clave: Poder, Gobierno, Política, Servidumbre.

\footnotetext{
${ }^{1}$ Magister de la Universidad Nacional de Rosario. Argentina. E-mail: andresyale@funescoop.com.ar
} 


\section{RESUMO}

Dois misteriosos enigmas recobrem os nexos entre os humanos e as relações políticas que eles mesmos criam. O primeiro se refere à relação desigual entre os que governam e as multidões governadas. Como é possível que as pessoas procurem ser governadas e controladas? Por que os homens lutam pela servidão como se fosse uma salvação? Estas interrogações foram formuladas por Étienne de La Boétie no século XVI. O outro enigma, em estreito vínculo com o anterior, alude a paixão ou amor pelo poder, ao laço que o homem estabelece com o poder; a sedução que o poder exerce sobre o homem que o detém. No presente ensaio buscaremos avaliar ambos os enigmas através da utilização, de um lado, das ideias contidas no Discurso da servidão voluntária e, de outro lado, dos conceitos foucaultianos de poder governo.

Palavras-chave: Poder, Governo, Política, Servidão.

\section{ABSTRACT}

Two mysterious enigmas veil the bonds between humans and the political relationships that they themselves create. The first is the unequal relationship between those who govern and the multitude governed. How is it possible that people seek to be governed and controlled? Why do men struggle for servitude as though it were a kind of salvation? These questions were raised by Étienne de La Boétie in the sixteenth century. The second enigma - which is closely linked to the first - alludes to the passion for or love of power, to the bond which men establish with power; the seduction which power exerts over men who hold it. In this essay we seek to evaluate both of these enigmas by means of the application of ideas contained in Discourse on Voluntary Servitude as well as the use of the Foucauldian concepts of power and government.

Key words: Power, Government, Politics, Servitude.

\section{RÉSUMÉ}

Deux mystérieuses énigmes recouvrent les liens entre les humains et les rapports politiques qu'ils se créent pour eux-mêmes. La première se réfère à la relation inégale entre ceux qui gouvernent et les masses gouvernées. Comment est-il possible que les gens cherchent à être gouvernés et contrôlés ? Pourquoi les hommes luttent-ils pour la servitude comme si celle-ci constituait leur salvation? Ces interrogations ont été 
formulées par Étienne de La Boétie au XVIème siècle. L'autre énigme, en étroite relation avec la première, est représentée par la passion ou l'amour du pouvoir, par le lien que l'Homme établit avec le pouvoir et la séduction que celui-ci exerce sur les individus qui le détiennent. Dans le présent essai, nous chercherons à résoudre ces deux énigmes par l'entremise, d'un côté, des idées contenues dans le Discours de la servitude volontaire, et de l'autre, des concepts foucaldiens de pouvoir et de gouvernement.

Mots-clés: Pouvoir, Gouvernement, Politique, Servitude.

\section{摘要}

在人类和人类创造的政治关系之间存在着两个不解之谜。第一个迷, 统治者和被统治的一大 群人的不平等关系, 具体来说就是, 为何人们希望被统治被控制? 为什么人们愿意为被奴役 , 争取被奴役的地位, 就像是得到了拯救一样? 这些疑问由16世纪的思想家 Étienne de La Boètie

提出。第二个迷, 与第一个迷紧密相关, 人们对权力的热衷, 人们和权力之间构建的纽带, 权力对权力拥有者的诱惑。本论文利用 ÉTIENNE DE LA BOÈTIE 的著作 “关于自愿奴役 “和福柯的著作”权力和统治”的思想和观念对政治家和政治实践中的两个不解 之迷做些分析。

关键字：权力，政府，政治，奴役

\section{Introducción}

Una advertencia inicial parece necesaria: es preciso dejar de lado la idea de que lo político se vincula necesariamente a los partidos, o peor aún, a individuos o grupos que así suelen adjetivarse. Lo político se vincula con las formas en las que en una sociedad determinada, se establecen, se favorecen o se niegan ciertas relaciones de poder. Es una manera de urdir relaciones asimétricas.

Dos misteriosos enigmas recubren los nexos entre los humanos y las relaciones políticas que ellos mismos crean. El primero atañe al carácter gregario de la vida comunitaria y más específicamente a la desigual relación entre los pocos que gobiernan y las multitudes gobernadas. ¿Cómo es posible que las personas procuren ser gobernadas, dominadas, dirigidas, controladas? ¿Por qué los hombres luchan por su servidumbre como si se tratara 
de su salvación? Estos interrogantes no son novedosos, fueron formulados por el joven francés Étienne de La Boétie en la mitad del siglo XVI.

¿Cómo es posible que la mayoría no sólo obedezca a uno solo, sino que también le sirva, y no tan sólo le sirva sino que también desee servirle? La sociedad en la que vivimos tiene dos grandes fracturas: una es la división entre los propietarios de medios de producción y los que no lo son. La otra, menos publicitada y más naturalizada, es entre los que mandan y los que obedecen, división que como todo lo humano tiene su historia y su lugar en la historia. Se trata de la irrupción histórica del Estado, momento en el que comienza la sumisión voluntaria de todos a uno solo; momento también de aparición de un mutilado hombre nuevo que ha perdido parte de sí mismo al perder su ser para la libertad. Paradoja de la historia: el único ser que posee los atributos para ser libre construye formas sociales en las que uno o unos pocos mandan y el resto, la inmensa mayoría, obedece voluntariamente, como si fuera lo más natural y agradable.

El otro enigma, en estrecho vínculo con el anterior, alude a la pasión o amor por el poder, al lazo que el hombre establece con el poder; la seducción que el poder ejerce sobre el hombre que lo detenta, que lo ejercita, que lo cuida de cualquier amenaza, que imagina y cree ver peligros para ese poder en cualquier parte, que quiere siempre, si es posible, acrecentarlo y hacerlo más efectivo².

Tema preocupante de la época moderna desde Maquiavelo hasta Foucault, el poder es en el sentido esencial de su existencia una forma de relación entre uno y los otros. Es precisamente Foucault quien ha mostrado cómo las relaciones de poder no se establecen sólo entre el Estado y los gobernados, sino que se integran en todas las relaciones sociales y constituyen las diferentes modalidades que esas relaciones asumen.

La fascinación incomparable que el poder ejerce se produce, sin embargo, en cualquier nivel en el que se establezca. En el presente ensayo intentaremos evaluar ambos enigmas a través de la utilización, por un lado, de las ideas contenidas en el Discurso de la servidumbre voluntaria y, por otro, de los conceptos foucaultianos de poder y de gobierno.

\footnotetext{
${ }^{2}$ El tema del amor al poder o de la pasión por él no es, evidentemente, un tema foucaultiano. Sin embargo se encuentran algunas referencias al respecto; "[...] las relaciones entre poder, deseo e interés son más complejas de lo que ordinariamente se piensa [...]. Este juego del deseo, del poder y del interés es todavía poco conocido". Foucault, Michel (1978). Microfísica del poder, Madrid: La Piqueta, p 79. O también: "La relación de poder está allí donde hay deseo; es, pues, una ilusión su denuncia en términos de represión y una vanidad la búsqueda de un deseo fuera del poder". Foucault, Michel (1987). Historia de la sexualidad I, Madrid: Siglo XXI, p-99-100.
} 


\section{La cuestión política en el pensamiento de Etienne de La Boétie}

Con mucha frecuencia Étienne de La Boétie ha sido ubicado como un defensor de los derechos populares frente a las pretensiones monárquicas de instaurarse sobre el derecho divino; en este sentido se ha hablado, a propósito del joven francés, de un exponente destacado del antimaquiavelismo del Renacimiento. Sin embargo, una lectura atenta del Discurso nos indica con inmediata claridad que su intención es otra, puesto que se trata, en esencia, de cuestionar la existencia misma del Estado y del gobierno. En otras palabras, más que defender la idea de un gobierno elegido y eventualmente controlado por el pueblo lo que de La Boétie pretende es mostrar cómo la estructura de las sociedades divididas, es decir, de las sociedades estatales, no representa ni una forma necesaria de organización social ni un progreso indispensable en relación a las sociedades primitivas. Como señalara con agudeza Pierre Clastres ${ }^{3}$.

La Boétie expresa los efectos de una pura oposición lógica: su Discurso remite a la afirmación implícita, aunque previa, de que la división no es una estructura ontológica de la sociedad y que, en consecuencia, antes de la aparición desventurada de la división social, había necesariamente, en conformidad con la naturaleza del hombre, una sociedad sin sumisión y sin opresión. 4

Los historiadores anarquistas tienen, de acuerdo a ello, razones precisas y suficientes para reivindicar el pensamiento laboeciano como un antecedente renacentista de las ideas ácratas.

El problema central que en el Discurso parece plantearse es el siguiente: si los hombres aman con espontaneidad y naturalmente la libertad, ¿cuáles son las razones por las que toleran que un solo hombre, que por lo general, además, suele ser débil y corrupto, los oprima y los reduzca a la servidumbre? Como afirma Homero (Ilíada, II, 204), tener muchos amos no es bueno, pero poseer uno sólo tampoco, ciertamente, lo es. A propósito de ello el propio La Boétie se pregunta: “¿Acaso no es una desgracia extrema la de estar sometido a un amo del que jamás podrá asegurarse que es bueno porque

\footnotetext{
${ }^{3}$ El antropólogo y etnólogo francés Pierre Clastres intenta demostrar que las sociedades primitivas son sociedades sin clases y sin Estado. Rechaza toda idea de evolución, de un cambio gradual que hubiera llevado de las sociedades sin Estado a las sociedades civilizadas con Estado. Entre ambas hay una ruptura, explicable en términos análogos a como Levi-Strauss explica el paso del pensamiento salvaje o de la reflexión mítica al pensamiento científico; el paso de una a otra implica un salto cualitativo, pero no necesariamente alguna clase de progreso.

${ }^{4}$ Clastres, Pierre (1980). Libertad, desventura, innombrable, Barcelona: Tusquets, p. 120-121.
} 
dispone del poder de ser malo cuando quiere? $Y$ obedeciendo a varios amos, ¿no se es tantas veces más desgraciado?’5

La condena que surge de estas palabras no se dirige específicamente, como podría creerse, a las monarquías absolutas que empiezan a consolidarse por casi toda Europa entre los siglos XV y XVI; lo que se cuestiona aquí es, en esencia, el poder político y su forma institucionalizada, a saber, el Estado. La virulencia del Discurso, la subversión que instaura con respecto a las ideas correspondientes a la necesidad del Estado, no pueden desactivarse atribuyéndolas a un cierto contexto, a un determinismo histórico cualquiera, o a una situación de época. La condición y los alcances de la pregunta que La Boétie formula la transforman en un interrogante transhistórico, libre como afirma Clastres- de toda 'territorialidad' social o política: ¿ cómo es posible que la mayoría no solo obedezca y se someta a uno sólo, sino que también le sirva y que además, desee servirle?.

En algunas ocasiones - admite La Boétie- un pueblo se ve sometido por la fuerza; en otras, mucho más infrecuentes, el pueblo se compromete por alguna razón a obedecer a alguien. Por fuera de estas dos circunstancias, lo que ocurre habitualmente es el hecho de que un número casi infinito de individuos se disponen voluntariamente para la servidumbre, siendo despojados de libertades y derechos que les son propios, pero que sin embargo están dispuestos a resignar masivamente. Pero tal actitud no es atribuible a la cobardía, en razón de que la naturaleza humana establece límites tanto para los vicios como para las virtudes, y es por ello que resulta inverosímil que tantos individuos padezcan del miedo a uno sólo, de la misma forma en que lo es que un solo individuo se enfrente a una multitud o que sojuzgue a un pueblo entero. En esto consiste entonces lo extraño de la cuestión. La salida que La Boétie encuentra es al parecer sencilla. Para finalizar con una tiranía no es indispensable, y ni siquiera necesario, luchar contra el tirano: resulta suficiente con no obedecerle, con no darle nada, mucho más que con quitarle algo. Un país puede no realizar ningún esfuerzo en procurarse la felicidad, si es que no la desea, pero lo que no debe hacer es forjarse su propia ruina sometiéndose a la voluntad de uno. Sin embargo, no es esto lo que sucede, ya que es el propio pueblo el que se somete y, pudiendo elegir entre la libertad y la servidumbre rechaza la libertad y escoge el yugo. Por eso es tan difícil comprender el comportamiento de pueblos enteros,

\footnotetext{
${ }^{5}$ La Boétie, Étienne de (1980). Discurso de la servidumbre voluntaria, Barcelona: Tusquets, p. 52.
} 
que - podría decirse- buscan afanosamente ser gobernados, a costa de su independencia y de su libertad, puesto que lo único que hace falta para recuperar la libertad es el deseo de recobrarla. La Boétie sigue en ello la doctrina estoica, puesto que cree - al igual que Epícteto o Marco Aurelio- que la libertad es un atributo natural del hombre, y tal vez también el más importante de ellos, puesto que es con la libertad con la que se relacionan todos los otros bienes de la vida humana. Se trata de una libertad que bien puede ser comprendida como 'autonomía', es decir, con la capacidad de actuar y de pensar con independencia de las coacciones de la comunidad o del Estado. La libertad es entonces el bien más importante, el más deseable y al mismo tiempo el más fácil de procurar y de conseguir puesto que basta con desearla para obtenerla; solamente es preciso que ese deseo sea auténtico:

Decidíos, pues, a dejar de servir, y seréis hombres libres. No pretendo que os enfrentéis a él -al tirano-, o que lo tambaleéis, sino simplemente que dejéis de sostenerlo. Entonces veréis cómo, cual un gran coloso privado de la base que lo sostiene, se desplomará y se romperá por sí sólo. ${ }^{6}$

Pero las cosas no se presentan tan simplemente en la realidad, en tanto los pueblos suelen no percibir la tiranía como una grave desventura. ¿A través de qué mecanismos, por medio de cuales procedimientos ha podido eliminarse o adormecerse un sentimiento tan naturalmente humano como es el deseo de libertad? La naturaleza nos ha hecho a todos de la misma forma, de manera tal que es necesario que nos reconozcamos como compañeros o como hermanos, y nos ha dado la tierra para que vivamos en ella, los más débiles junto con los más fuertes, los que están en disposición de dar ayuda junto a los que tienen necesidad de recibirla, más no como siervos unos de otros, sino bajo el amparo de una relación fraterna. También a todos nos ha sido otorgada la voz y la palabra $^{7}$ para unirnos y profundizar los vínculos de amistad, y en todas las cosas la naturaleza ha querido - afirma La Boétie- estrechar las formas de nuestra alianza, de nuestra fraternidad, de nuestra camaradería. La libertad es entonces algo natural en el hombre, tanto como lo es el luchar por ella. Si esta idea no consigue, sin embargo, convencer a todos, el joven autor del Discurso pone como ejemplo a los animales,

\footnotetext{
${ }_{7}^{6}$ La Boétie, E. de (1980). Op. Cit., p. 60-61.

${ }^{7}$ Cabe recordar aquí que de acuerdo a lo que afirma Agamben, (Ver: Agamben, Giorgio. (2001). Medios sin fin. Notas sobre la política, Valencia: Pretextos) el vínculo entre el factum loquendi y el factum pluralitatis, es decir, entre el hecho de hablar y el hecho social, constituye el fundamento de la teoría política moderna. Ejemplos de ellos son las doctrinas contractualistas que ven el fundamento y la legitimidad del orden estatal como un pacto de cada hombre con los demás. La Boétie, sin embargo, parece situarse en las antípodas de esta concepción, pues la palabra es una herramienta de alianza y de amistad, y no el medio por el cual se delega en otros ningún derecho.
} 
modelos de vida en acuerdo con la naturaleza, sin rangos, jerarquías o clases, que el hombre que se pretenda justo y sabio debería imitar": "Es sabido que algunas bestias mueren tan pronto como son apresadas. Al igual que el pez que pierde la vida cuando se le saca del agua, muchos animales se dejan morir para no sobrevivir a su libertad natural perdida', Sin embargo, la libertad natural en el hombre ha sufrido un accidente trágico, una desventura que ha conducido a que "el único ser nacido de verdad para vivir libre" haya incluso perdido el recuerdo de su estado original tanto como el deseo de retornar a él.

En la naturaleza del hombre existe una inclinación a amar y a prestar obediencia a los padres - o a quienes ocupen o cumplan la función de tales- y a seguir lo que la razón aconseja o dictamina, en tanto nuestra alma es de carácter racional y es en ella en donde se encuentran en estado potencial todas las verdades. Sin embargo, no hay nada en nuestra naturaleza que induzca a actuar como siervo de otro; nada hay más claro en esa naturaleza que la igualdad humana, en tanto todos los seres hemos sido, por así decirlo, producidos de la misma manera y con el mismo molde ${ }^{10}$. La igualdad originaria de los hombres es por lo tanto innegable. Por supuesto, las condiciones políticas en las que esta afirmación se realiza le otorgan una validez y una osadía que difícilmente se encuentre en otro discurso filosófico y político de mediados del siglo XVI, el siglo de Maquiavelo y de Hobbes, el siglo en el que la Iglesia Católica tanto como la Iglesia Luterana propician y bendicen la consolidación de las monarquías absolutas de Enrique VIII o de Felipe II.

Pero lo importante es que con insospechada facilidad tienden los hombres a prescindir rápidamente de su libertad. La Boétie señala que la primera causa de la servidumbre en la que caen los hombres es el hábito; aquellos que han vivido siempre bajo el imperio de un gobierno tiránico ignoran por completo lo que la libertad es y se someten creyendo que ese es el estado natural de los hombres, puesto que hacen ni más ni menos lo que han visto hacer a sus progenitores y a sus antepasados en general. La naturaleza es un elemento determinante en la condición humana, pero más aún lo son la educación y las costumbres.

\footnotetext{
${ }^{8}$ En este punto - el de la comparación entre hombres y animales - La Boétie sigue sin duda las ideas cínico-estoicas del autor de las Epístolas pseudo-heraclíteas, para el cual la vida y las costumbres de los animales pueden erigirse en norma de la vida y de las costumbres humanas.

${ }^{9}$ La Boétie, E. de (1980). Op. Cit., p. 63-64.

${ }^{10}$ Nuevamente encontramos en las ideas de La Boétie la reproducción de las tesis estoicas, de Séneca, de Zenón, y especialmente de Marco Aurelio. Para éste último todos los seres obran en el Universo de acuerdo a su propia estructura o naturaleza, siendo el primer carácter de la naturaleza humana la sociabilidad. Ver: Marco Aurelio, Soliloquios, X, 6.
} 
La segunda de las causas por las cuales los hombres están en condiciones de perder su libertad es la cobardía y el envilecimiento que produce en ellos el poder tiránico, que genera hombres que carecen de valor y de atrevimiento. Por esa razón - dice el francés- quienes están esclavizados o sometidos van a la guerra sin entusiasmo, sin alegría y sin coraje, mientras que los hombres libres desprecian el peligro y luchan juntos fraternalmente, haciéndose cargo conjuntamente tanto de la victoria como de la derrota. Los tiranos conocen este hecho, este ablandarse el ánimo de los sometidos, y es por esa razón, además de prohibir libros y de perseguir el saber, que proporcionan la capacidad de reconocer el estado de servidumbre como un mal innecesario y por tanto de odiar a la tiranía, que fomentan el teatro, los juegos y los espectáculos en general. La tercera de las causas de la servidumbre voluntaria radica en el temor a lo desconocido y a lo que se presenta como misterioso. Con el objetivo de reforzar el sometimiento de los súbditos los gobernantes apelan a rodearse de misterio y a atribuirse características o sobrenaturales o en todo caso diferentes a los demás seres humanos. En este sentido, las ideas religiosas constituyen una suerte de escudo que protege a los gobernantes de las rebeliones; en esto La Boétie se anticipa a sus compatriotas franceses, los iluministas del siglo XVIII. ${ }^{11}$.

Además de determinar las causas por las cuales se produce el sometimiento y la sujeción de los pueblos, el joven francés analiza lo que podríamos llamar la maquinaria del poder político. Más que en las armas, se teje alrededor del gobernante toda una red de complicidades que va creciendo en forma geométrica en cuanto se aleja del poder central y se extiende a los poderes regionales y luego locales. El tirano reduce a servidumbre a sus súbditos a través de otros, en lo que constituye la conformación de una pirámide en la que se asienta y toma forma el poder político.

Como decíamos al comienzo del presente ensayo, Étienne de La Boétie y su Discurso de la servidumbre voluntaria ha sido valorado de maneras diferentes y hasta antitéticas. A. Vermorel, que publica en 1835 una edición comentada del Discurso, declara en su prefacio que se encuentra allí un '[...] amor tranquilo y sereno de la libertad y una previsión de la fraternidad social que lo acercan mucho más a nuestras simpatías

\footnotetext{
${ }^{11}$ El más virulento representante del humanismo antirreligioso del enciclopedismo, D’Holbach, afirma que quien combate las ideas del catolicismo es "[...] un hombre que destruye quimeras dañinas para el género humano, para hacer volver a los hombres a la Naturaleza, la experiencia y la razón". D'Holbach, P.H. Sistema de la Naturaleza, Madrid: Ed. Nacional, p. 557.
} 
modernas y que hacen de él un genuino clásico de la tradición liberal y democrática"12. Pierre Leroux, por su parte, cree que el Discurso "es una bella declamación filosófica y republicana: pero no es más que una declamación", y al igual que Montaigne, opina que se trata de una obra "verdadera en sus principios, espléndida en la belleza de sus ideales, pero impotente para realizar la meta que allí se señala"13. En una posición diferente Max Nettlau (1978) y aún otros historiadores ácratas lo consideran un verdadero precursor de la filosofía política anarquista. Pierre Clastres, como se ha señalado arriba, advierte que la obra de La Boétie contiene la afirmación fundamental acerca de la efectiva historicidad de las sociedades estatales, es decir, la afirmación de que las sociedades divididas entre gobernantes y gobernados no existieron desde siempre y necesariamente. Lo que para el joven francés no podía ser sino un saber a priori hoy es el objeto de un conocimiento producto no ya de la deducción lógica sino de la observación directa. La etnología trabaja detrás del umbral que delimitan las sociedades estatales, sobre aquellas sociedades anteriores a la civilización, a la escritura, a la Historia, las primeras en desarrollarse en la ignorancia de la división entre gobernantes y gobernados; "El objeto privilegiado, si no exclusivo, de la etnología es hoy en día el estudio de las sociedades sin Estado"14. Y por pensar, tal vez por vez primera, en las condiciones en las que el hombre debe vivir tras la fractura social que impone la aparición del Estado, Clastres lo considera el creador no reconocido de la antropología del hombre moderno, y el precursor de la tarea que se imponen K. Marx y aún en mayor medida F. Nietzsche "de pensar la decadencia y la alienación ${ }^{\prime 15}$.

\section{Sociedades no estatales}

El enigma de lo que La Boétie menciona como la desnaturalización, y la posibilidad de establecer tal desnaturalización como un movimiento regresivo hacia la animalidad, residen en el extraño hecho de que los hombres, al parecer, obedecen de forma voluntaria. Para que lo hagan no es necesario - salvo excepcionalmente- ni el uso de la fuerza, ni la aplicación del terror ni la promesa de un castigo; los hombres obedecen

\footnotetext{
${ }^{12}$ Vermorel, A. (1835), prefacio a De la servitute volontaire ou Le Contr'un par Étienne de La Boétie, Paris, citado por Abensur, M.; Gauchet, M. (2009). "Presentación". In La Boétie, Étienne de (2009). El Discurso de la servidumbre voluntaria, La Plata: Terramar.

${ }_{13}$ Leroux, P. (2009). El 'contra uno' de Etienne de La Boètie, La Plata: Terramar, p. 88-89.

${ }_{15}^{14}$ Clastres, P. (1980). Op. Cit., p. 121.

${ }^{15}$ Clastres, Pierre (1979). "La voluntad de ser siervo". In El viejo topo, 32, p. 56-57.
} 
porque eligen hacerlo, eligen, para utilizar otro término que designa de forma más general lo mismo, la alienación, tras el proceso en el cual la voluntad de ser libres es sustituida por el deseo de servidumbre. Ahora bien: cabe preguntarse si este deseo de sumisión se corresponde con los contenidos inmanentes a la naturaleza humana - en cuyo caso habría que indagar sobre la coexistencia en ella de dos deseos orientados en sentidos contrarios- , o si su aparición histórica debe considerarse, extrañamente, ex nihilo, como una misteriosa y desgraciada mutación en la naturaleza humana que se muestra refractaria a cualquier explicación racional.

Como el propio Clastres indica, las sociedades que llamamos primitivas son sociedades que no tienen Estado. Esta afirmación, sin embargo, debe considerarse cuidadosamente, puesto que contiene dos peligros que es necesario conjurar. En primer lugar, la denominación 'sociedades primitivas' denota una inexacta y tendenciosa consideración de las estructuras sociales anteriores a la formación del Estado y a la división de la sociedad en clases, puesto que refiere a las nociones de 'evolución', 'desarrollo' y 'progreso', que por su parte sintetizan una concepción teleológica de la historia humana y la necesariedad del camino que han tomado las sociedades contemporáneas. En segundo lugar, mencionar a aquellas sociedades como 'sin Estado' es referirse a ellas como privadas de algo que les sería, antes o después, indispensable. Serían sociedades, entonces, que padecen de una carencia, sociedades todavía incompletas, en las existe un vacío que no pudieron o no supieron llenar, puesto que el Estado constituye siempre el destino de toda sociedad. Se trata claramente, según nuestra opinión, de un visión etnocéntrica para la cual la historia posee un único sentido en el debe producirse el 'desarrollo', desde las épocas de barbarie hacia la civilización. De hecho, las sociedades arcaicas, pretéritas, merecen siempre denominaciones negativas que aluden a lo que esas sociedades aún no tenían, porque no sabían, porque todavía no podían; sociedades sin Estado, pero también sociedades sin escritura y sin historia. Sin embargo si las sociedades primitivas eran sociedades sin Estado - como afirma taxativamente Clastres- no era de ninguna manera por alguna especie de incapacidad congénita para llegar a la edad adulta de la estatalidad; por el contrario, estas sociedades rechazaban, como producto de una decisión colectiva, la constitución de una autoridad central y permanente, rechazaban de forma deliberada la obediencia. De igual modo se suele afirmar que las economías de las sociedades pre-estatales eran 'economías de subsistencia', en las que, por carecer de excedentes, no existía el mercado. Nuevamente 
una carencia, nuevamente un equívoco intencionalmente provocado. Las sociedades arcaicas no producen excedentes porque no pueden, porque son incapaces, porque se encuentran todo el tiempo ocupadas en producir lo mínimo requerido para la supervivencia, y esto ocurre por ignorancia técnica, por su escasa provisión tecnológica. La comprensión moderna del término técnica ocupa aquí el centro de la escena: si por ello se entiende, a la manera de Descartes, el dominio aplastante e ilimitado de la naturaleza, en el cumplimiento del mandato baconiano del deber ser 'amo y señor' del mundo natural, entonces es cierto que las sociedades arcaicas se encuentran técnicamente muy relegadas. Pero si por técnica se entiende la capacidad de asegurar un cierto dominio de los recursos que la naturaleza ofrece en relación con las necesidades, aquellas sociedades eran tan o más capaces de satisfacerlas como lo son (aunque como se sabe, sólo para algunos) las sociedades industriales modernas. No hay, entonces - como afirma Clastres - ninguna "jerarquía en el campo de la técnica, no hay tecnología superior ni inferior; no puede medirse un equipamiento tecnológico sino por la capacidad de satisfacer, en un medio dado, las necesidades de la sociedad"16.

Está claro que la servidumbre voluntaria, o en otras palabras, el deseo de sumisión debe ser correlativo al deseo de poder. No hay posibilidad de realización del deseo de mandar sin el correlato necesario del deseo de obedecer. Se trata entonces de una cuestión dialéctica, en la que la existencia de uno está determinada por la existencia del otro, aunque como lo señala Claude Lefort, será necesario comprender que '[...] de la servidumbre a la libertad no hay transición alguna en lo real; ni espacio, ni tiempo que recorrer, ningún esfuerzo, ninguna acción: tan sólo se da una versión del deseo,17. Un problema de deseo; recordemos la afirmación laboeciana de que no es necesario ni indispensable luchar en contra del tirano para deshacerse de él. Si no se les da nada, si se les niega todo, no es preciso combatirlos, pues "se quedan desnudos y derrotados y ya no son nada". Es entonces en el deseo de los pueblos en donde los amos viven o perecen, se hacen cada vez más fuertes o se desintegran. Una vez que se nombra el deseo de servidumbre, de inmediato aparece como el objeto de un deseo. Pero también sabemos que el hombre es en algún momento libre, al menos en tanto le es posible elegir entre la libertad y la servidumbre. La pregunta insiste y muestra ya algo de su complejidad. ¿Por qué enigmáticas razones, teniendo esa posibilidad de ser libre, los

\footnotetext{
${ }^{16}$ Clastres, Pierre (1978). La sociedad contra el Estado, Caracas: Monte Ávila, p. 167.

${ }^{17}$ Lefort, C. (1980). El nombre de uno, Barcelona: Tusquets, p.142.
} 
hombres eligen el sometimiento y rechazan su libertad? Al parecer - y esto es lo que extraña y repugna todo el tiempo a La Boétie- los hombres finalmente desean la servidumbre. Lo que ocurre, y lo que revela una lectura atenta y rigurosa del Discurso es, al parecer, lo siguiente; al oponer deseo de servidumbre a deseo de libertad lo que se establece resulta ser nada más y nada menos que el carácter social del deseo humano. En toda la parte inicial de la obra las apelaciones que el autor realiza se refieren explícitamente al pueblo, a su libertad y a su servidumbre, al tirano o al príncipe, Pero cuando La Boétie interpela de forma directa al pueblo se muestra la grieta que existe entre la consideración de éste pueblo y el Hombre y su hipotética naturaleza. Dice el autor:

Hay una sola cosa, que los hombres, no sé por qué, no tiene ni siquiera la fuerza de desear: la libertad, ese bien tan grande y placentero cuya carencia causa todos los males. Los hombres sólo desdeñan, al parecer, la libertad, porque de lo contrario, si la desearan realmente, la tendrían. Actúan como si se negaran a conquistar tan precioso bien únicamente porque se trata de una empresa demasiado fácil' ${ }^{1}$.

Notemos de pasada el desliz producido en el lenguaje y las modificaciones sustanciales que allí, entonces, se producen. Una cosa es la supuesta naturaleza del Hombre, y algo distinto es el pueblo como conjunto, como comunidad, como entidad social. Las palabras inducen a creer que la libertad, es, según nuestro autor, natural en el hombre, aunque esto no significa que el deseo de libertad, que se constituye en una dimensión social, también lo sea.

En cuanto a los mecanismos que producen la posibilidad de la dominación, al menos en sus aspectos fenoménicos, no parece haber demasiadas dudas. La dominación depende del deseo, que opera en cada uno más allá de la posición en la jerarquía social que ocupe, de identificarse con el tirano transformándose imaginariamente en el amo de otros. La identificación con el tirano, con el gobernante, atraviesa la red social de cabo a cabo, de manera que hasta el más miserable de todos puede también creerse él mismo un dios. Cada hombre, entonces, constituido en su vínculo social por la identificación con el amo-tirano-gobernante, se convierte a su vez en minúsculo tirano frente a los demás.

Por otra parte, es necesario reconocer - o recordar, puesto que los anarquistas lo repiten desde al menos el siglo $\mathrm{XIX}^{19}$ - que esta oposición entre quien manda y quien

\footnotetext{
${ }^{18}$ La Boétie, E. de (1980). Op. Cit., p. 58.

19 Ver: Bakunin, M. (2004). Dios y el Estado, Barcelona: El viejo topo, o Proudhon, P. (2005) ¿Qué es la propiedad?, Buenos Aires: Libros de Anarres.
} 
obedece, es correspondiente con otra división, por cierto más publicitada. Se trata naturalmente de la división entre los que poseen los medios de producción y los trabajadores, asalariados, cuentapropistas o desempleados. La Boétie nos dice que

[...] cuando un rey se transforma en tirano, todo lo malo, toda la hez del reino - y no me refiero a ese montón de ladronzuelos y desorejados, que casi no pueden, en una república, hacer ni mal ni bien, sino a los que arden de ambición y son de una notable avaricia- se amontonan a su alrededor y los sustenta para tener parte en el botín, y bajo el gran tirano convertirse ellos mismos en pequeños tiranos ${ }^{20}$.

Estos hombres del siglo XVI no se comportan de manera muy disímil a nuestros contemporáneos, construyendo al parecer un ejemplo más del casi célebre homo oeconomicus del que, con otro nombre, hablara ya Aristóteles ${ }^{21}$ y mucho más tarde Adam Smith $^{22}$. Hay que decir también que la utilización del lenguaje clásico ha hecho que en el Discurso se mencione repetidamente, hasta casi el final de la obra, al tirano como el objeto privilegiado de la crítica y el escarnio. Sin embargo, creemos que esto señala solamente un problema de nombres, y que el sentido y la intención crítica que el texto contiene se dirige contra la esencia de lo que hoy podríamos denominar dominación. De lo que se trata en él, según nuestro juicio, es de un cuestionamiento efectuado bajo el signo de una rigurosidad implacable a las formas de organización política que establecen una sociedad dividida entre quienes mandan y quienes son siervos, entre quienes gobiernan y quienes obedecen. Al mismo tiempo, La Boétie pretende sugerir otra forma en la que lo político - y sin que esto implique ninguna proposición revolucionaria, ninguna propuesta de acción efectiva- pudiera establecerse, vinculada al ejercicio de la 'amistad' y del 'compañerismo'. Dos formas opuestas en la que lo político pudiera ser construido, dos formas opuestas de organización de la sociedad. En una de ellas la relación entre los hombres esta signada por la 'conspiración', por el enfrentamiento, por la rivalidad y por el interés individual y el temor al otro. En la otra lo que organiza el vinculo social es el 'compañerismo', la amistad, el reconocimiento del otro, y el 'mutuo amor'. Y es que efectivamente, la amistad posee un claro sentido político; se establece en una relación que, en lo que tiene de esencial, se funda en la negación de la trascendencia del amo, y

\footnotetext{
${ }^{20}$ La Boétie, E. de (1980). Op. Cit., p. 74.

${ }^{21}$ Ver: Aristóteles. Política, Libro II, V.

${ }^{22}$ Adam Smith escribió, a propósito del interés económico que prima por sobre cualquier otra inclinación humana: "No es la benevolencia del carnicero, del cervecero o del panadero la que nos procura el alimento, sino la consideración de su propio interés". Smith, A. (2005). Investigación sobre la naturaleza y las causas de la riqueza de las naciones, México: F.C.E, p. 17.
} 
en la que éste no tiene ninguna ingerencia, puesto que para La Boétie el poder está separado del pueblo, y sea cual sea el carácter del príncipe y sus capacidades para gobernar, no dependen de él las condiciones en las que se producen las relaciones de amistad, que escapan a su dominio.

Finalmente, el Discurso termina con un ataque directo a las clases dominantes, tal vez en la reafirmación de que no es precisamente el príncipe o el tirano el que se encuentra en el origen de la sumisión; se trata -mucho más que de eso- del funcionamiento de las máquinas sociales y de los complejos mecanismos que, entre el deseo de sumisión y el deseo de libertad, ellas engendran.

\section{Poder, gobierno y Estado en el pensamiento de M. Foucault}

Como es sabido, el problema del poder es uno de los problemas centrales del pensamiento de Foucault, y es también el objeto privilegiado en la reflexión de una muy extensa nómina de filósofos modernos, que va desde Rousseau hasta Nietzsche, pasando por Hegel, y desde Locke hasta Marx, pasando por Proudhon.

Tal vez uno de los rasgos más singulares del pensamiento de Foucault consiste en la adopción de una perspectiva genealógica, lo cual implica entre otras cosas la posibilidad de efectuar un análisis del saber en términos de estrategias y tácticas de poder, es decir, de ubicar al saber en un campo de luchas. La condición de posibilidad de la genealogía es la supresión de lo que Foucault denomina "la tiranía de los discursos globalizantes con sus jerarquías y todos los privilegios de la vanguardia teórica,23. Esta condición implica una desconfianza total en la categoría de totalidad, categoría que resulta el presupuesto necesario de toda ontología y de toda metafísica desde los filósofos presocráticos hasta, al menos, Hegel. Habría que decir que sería necesario examinar tal desconfianza con detenimiento y exhaustivamente, tanto como para otorgar, tal vez, un sentido renovado al pensamiento foucaultiano como para abrir las puertas a una posible nueva ontología o a una novedosa también forma de pensar al ser y a la totalidad. Foucault se pregunta:

Qué es este poder cuya irrupción, fuerza y despliegue, y cuyas medidas de seguridad han aparecido en el curso de los últimos cuarenta años en el estallido del nazismo y en el retroceso del stalinismo? ¿Qué es el poder, o más bien puesto que sería justamente el tipo de pregunta que quiero evitar (es decir, la

\footnotetext{
${ }^{23}$ Foucault, Michel (1986a). Genealogía del racismo, La Plata: Altamira, p. 17-18.
} 
pregunta teórica que coronaría el conjunto)- cuáles son en sus mecanismos, en sus efectos, en sus relaciones, los diversos dispositivos de poder que se ejercen, en distintos niveles de la sociedad, en sectores y con extensiones tan variadas? ${ }^{24}$

En el contexto de la genealogía, Foucault se plantea un problema que constituye el núcleo central de la mayoría de las discusiones producidas en el marco de la filosofía política desde la emergencia de las primeras manifestaciones del pensamiento socialista. Tales disputas se producen entre los defensores del contractualismo, por una parte, y los socialistas de las diferentes tendencias, por otra; entre éstos últimos, el debate genera a su turno una división entre centralistas y federalistas, es decir entre marxistas y anarquistas. La pregunta formulada se refiere, precisamente, al análisis del poder; ¿Puede éste, de una forma o de otra, deducirse de la economía?

Foucault se da cuenta de que, a pesar de las abismales diferencias, hay un elemento en común entre las concepciones liberales y jurídicas del poder político - las concepciones de Rousseau, de Locke, de Montesquieu- y la concepción marxista; el punto en común es el economicismo que domina la teoría del poder. Entre los liberales, el poder es considerado como un derecho que se posee al modo de un bien y que por lo tanto se puede alienar o transferir a través de un acto jurídico. Entre los marxistas, el poder cumple con la finalidad de mantener las relaciones de producción y la dominación de una clase sobre la otra, es decir, el poder político tiene su razón de ser en la economía. De esta forma, en las ideas liberales el poder económico se constituye en el modelo del poder político, mientras que entre los marxistas es el fundamento del mismo.

Pero Foucault se pregunta si el poder está subordinado siempre y necesariamente a la economía ${ }^{25}$, y si en sus formas de ejercicio, participa del modelo que regula el funcionamiento económico, es decir que es algo que se adquiere, o se posee, o se cede o se expropia ${ }^{26}$. En torno a esta última cuestión debemos recordar que para el contractualismo liberal el poder es algo que participa del modelo de la economía (se posee o se cede, por la fuerza o por otros medios), mientras que para el pensamiento

\footnotetext{
${ }^{24}$ Ibidem.

${ }^{25}$ Hay que recordar, en este punto, que el pensamiento socialista del siglo XIX se interrogó sobre ambos problemas y propuso para ellos diferentes soluciones. La polémica entre marxistas y bakuninistas da cuenta de este problema. Los primeros creen que el poder político y el Estado son una superestructura de las relaciones de producción. Los segundos consideran que el Estado es la estructura básica sobre la cual se establecen las relaciones de producción que suponen la explotación del trabajo. Para los anarquistas, política y economía se condicionan mutuamente, pero en el origen histórico hay siempre en primer lugar un acto político.

${ }^{26}$ Foucault, M. (1986a). Op. Cit., p. 28.
} 
socialista el poder es una cualidad inmanente a al sociedad, previa a la diferenciación entre quien lo ejerce y quien lo padece.

Para Foucault, en cambio, el poder no es objeto de ningún intercambio, sino que se ejerce y solamente existe en tanto actúa, al mismo tiempo que no resulta - al menos privilegiadamente- una entidad destinada al mantenimiento y a la reproducción de las relaciones económicas puesto que se trata ante todo de una relación de fuerzas. Desestimando la 'hipótesis represiva' en cuanto a la mecánica y al ejercicio del poder ${ }^{27}$, Foucault afirma ${ }^{28}$ que el poder debe ser analizado, como despliegue de una relación de fuerzas, en términos de lucha, de enfrentamiento, de guerra. Esta es la hipótesis de Nietzsche y supone una inversión de la tesis de Clausewitz de acuerdo a la cual la política es la continuación de la guerra. Hay que notar que esta tesis se remonta a la sofística griega y es discutida por Platón en República, en su refutación a Trasímaco. Mas adelante, sin embargo, Foucault abandona parcialmente esta concepción y la reformula en términos de gobernabilidad. En el texto Genealogía del racismo precisamente, Foucault pone a prueba lo que él mismo denomina la 'hipótesis Nietszche', pero no sería conveniente ver allí una posición definitiva del autor con respecto al poder, puesto que tiempo después escribirá:

El poder, en el fondo, es menos del orden del enfrentamiento entre dos adversarios o del compromiso de uno frente al otro que del orden del gobierno. [...] Las relaciones propias del poder, por eso mismo, no podrían ponerse en un campo de violencia o de lucha, ni en uno de vínculos voluntarios (todos los cuales pueden ser, en el mejor de los casos, sólo instrumentos de poder), sino más bien en el área del modo de acción singular, ni belicoso ni jurídico, que es el gobierno. $^{29}$

El término 'gobierno' no designa en Foucault sólo las estructuras políticas o la dirección de los Estados, sino que también se refiere a la forma en la que puede dirigirse la conducta de otros, ya se trate de individuos o de grupos. En tal sentido es que es legítimo hablar del gobierno de los niños, de los enfermos o de las almas, por ejemplo. Gobernar, entonces, es estructurar un campo posible de acciones para los otros, un modo de acción sobre las acciones de otros hombres. Definido de esta forma, el problema del ejercicio del poder a través de las prácticas de gobierno trae aparejado, de forma

\footnotetext{
${ }^{27}$ La hipótesis represiva alude al funcionamiento del poder esencialmente como represión - de las clases, de los individuos, de la sexualidad, de los instintos. Es la hipótesis de Reich y de alguna manera también de Freud, pero es posible remontarla a Hegel.

${ }^{28}$ Foucault, M. (1986a). Op. Cit, p. 29-30.

${ }^{29}$ Foucault, Michel (1986b). Por qué hay que estudiar el poder: la cuestión del sujeto, Madrid: La Piqueta, p. 254.
} 
inmediata, el problema de la libertad. El poder se puede ejercer solamente sobre sujetos libres que tienen delante de sí un campo de posibilidades de acción y de comportamiento. No hay, por lo tanto, una confrontación directa entre poder y libertad; entre ellos, señala Foucault, hay una serie de interrelaciones en las que la libertad aparece como la precondición para el ejercicio del poder, y también como su fundamento constante, pues si no hay libertad hay determinación física, como en el caso de la esclavitud. Por estos motivos,

[...] las relaciones entre el poder y el rechazo de la libertad a someterse no pueden separarse. El problema crucial del poder no es el de la servidumbre voluntaria (¿cómo podríamos procurar ser esclavos?). El verdadero centro de las relaciones de poder es la reluctancia de la libertad y la intransigencia de la libertad. $^{30}$

Es necesario ahora agregar que, como resultado de sus indagaciones históricas y de su crítica de la 'hipótesis represiva' Foucault ve en el poder una instancia positiva, que fabrica o produce formas determinadas de individualidades. En contra de la tradición cartesiana, para él el sujeto no es una sustancia sino solamente una forma que no es sobre todo ni siempre igual a sí misma, que más que una instancia de fundación resulta el efecto de una constitución, o lo que es lo mismo, en términos de Foucault, de ciertos modos de subjetivación. Se trata de formas en las que se objetiva al sujeto, es decir, de formas en las que el sujeto aparece como objeto de una determinada relación de conocimiento y de poder.

El indudable mérito de los análisis foucaultianos de las relaciones de poder radica según nuestra opinión- en revelar su multidimensionalidad, su inacabable capacidad para reproducirse, para institucionalizarse en los más diferentes ámbitos de la vida social, y en mostrar cómo el manicomio, la cárcel, el hospital o la escuela son el producto definido de esa institucionalización, abordando un registro histórico ignorado casi por completo por la historia, la filosofía política y la sociología. Sin embargo Foucault excluye en su análisis de los poderes el poder central que es el poder del Estado, del que se deriva originalmente el poder económico que luego, en una instancia posterior, lo funda y lo soporta.

La idea de totalidad es legítimamente criticada por Foucault, en tanto su uso implica la afirmación de pseudo-totalidades. Pero la idea de totalidad es difícilmente separable del pensar filosófico e incluso del pensar mismo, pues como ya lo indicaron muy tempranamente Parménides y Heráclito, 'ser' es ser uno y ser todo.

\footnotetext{
${ }^{30}$ Ibidem, p. 255.
} 
Por otra parte, ni el Estado ni el capitalismo son pseudo- totalidades: resulta imposible, sin ellos, pensar de una manera adecuada y comprensible las relaciones de poder parcial, aquellas que se visibilizan en la escuela, el cuartel, el hospital, o las cárceles.

Es cierto que el poder no es el producto de un pacto o de una convención, pues se trata de una cualidad esencial de toda sociedad humana. Cada individuo y cada grupo disponen de un poder más o menos extenso de acuerdo a sus disposiciones físicas e intelectuales, pero tales diferencias no son de por sí demasiado notables. En las sociedades primitivas que mencionan Clastres y de La Boétie el poder es un poder indiviso, internalizado de manera equivalente en todos los individuos. Sin embargo, en un momento determinado, el poder de los individuos y de los grupos comienza a concentrarse en pocas manos, a través de una delegación que se hace pronto una cesión definitiva; el poder se fractura y se produce el nacimiento de la sociedad dividida, el nacimiento del Estado como forma de la sociedad jerárquica y coactivamente organizada. Esta forma de organización produce de manera inmediata, y necesariamente, la aparición de la propiedad privada, las diferencias de clase, la dominación y la sumisión. Pero al mismo tiempo nace también la lucha en contra de la sumisión y en contra de la dominación, la -al parecer- interminable lucha por restituir al hombre a su libertad originaria, en una sociedad no dividida, lo cual significa una sociedad sin propiedad privada, pero también sin Estado.

\section{Referencias}

Agamben, Giorgio. (2001). Medios sin fin. Notas sobre la política, Valencia: Pretextos.

Bakunin, M. (2004). Dios y el Estado, Barcelona: El viejo topo.

Clastres, Pierre (1978). La sociedad contra el Estado, Caracas: Monte Ávila.

(1979). "La voluntad de ser siervo". In El viejo topo, 32, p. 56-57.

(1980). Libertad, desventura, innombrable, Barcelona: Tusquets.

D’Holbach, P.H. Sistema de la Naturaleza, Madrid: Ed. Nacional.

Foucault, Michel (1986a). Genealogía del racismo, La Plata: Altamira.

Piqueta.

(1986b). Por qué hay que estudiar el poder: la cuestión del sujeto, Madrid: La 
La Boétie, Étienne de (1980). Discurso de la servidumbre voluntaria, Barcelona: Tusquets.

Lefort, C. (1980). El nombre de uno, Barcelona: Tusquets.

Leroux, P. (2009). El 'contra uno' de Etienne de La Boètie, La Plata: Terramar.

Proudhon, P. (2005) ¿Qué es la propiedad?, Buenos Aires: Libros de Anarres.

Smith, A. (2005). Investigación sobre la naturaleza y las causas de la riqueza de las naciones, México: F.C.E, p. 17.

Recebido para publicação em junho de 2013.

Aprovado para publicação em agosto de 2013. 